\title{
Evaluation of the importance of ornamental plants for pollinators in urban and suburban areas in Stuttgart, Germany
}

\author{
Melanie Marquardt ${ }^{1}$ (D) $\cdot$ Lydia Kienbaum $^{1} \cdot$ Lea Annina Kretschmer ${ }^{1} \cdot$ Anja Penell $^{1} \cdot$ Karsten Schweikert $^{2}$. \\ Ute Ruttensperger ${ }^{3} \cdot$ Peter Rosenkranz ${ }^{1}$
}

Accepted: 13 December 2020 / Published online: 26 December 2020

(C) The Author(s) 2020

\begin{abstract}
Urban landscapes are often characterized by a wide range of diverse flowering plants consisting of native and exotic plants. These flower-rich habitats have proven to be particularly valuable for urban pollinating insects. However, the ability of ornamental plants in supporting urban pollinator communities is still not well documented. For this study, we established flower beds at 13 different urban testing sites, which were planted with identical sets of ornamental garden plants. The pollinator visitation patterns were then observed throughout the summer seasons. Over a two-year period, a total of 10,565 pollinators were recorded with wild bees (> 50\%, excluding bumblebees) being the most abundant pollinator group. Our results revealed that (I) the assortment of ornamental plants was visited by a high number of urban pollinators for collecting pollen and nectar, and (II) the pollinator abundance and composition varied significantly within the tested ornamental plants. These differences occurred not only among plant species but to the same extent among cultivars, whereby the number of pollinators was positively correlated with number of flowering units per plant. By using a generalized linear mixed model (GLMM) and redundancy analysis (RDA) we identified further significant impacts of the two variables year and location on the insect pollinator abundance and richness. Despite of the local and yearly variations, our approach provided a good and field-applicable method to evaluate the pollinator friendliness in ornamental plants. Such tools are urgently required to validate labels like 'bee friendly' or 'pollinator friendly' used by plant breeding companies.
\end{abstract}

Keywords Ornamental plants $\cdot$ Urban landscape $\cdot$ Pollinators $\cdot$ Impact factors

\section{Introduction}

For many years, biologists and ecologists are alarmed by the ongoing global decline in biodiversity (Barnosky et al. 2011; Ceballos et al. 2017) and recent publications impressively confirm that insect biodiversity is in the middle of this process (e. g. Hallmann et al. 2017; Powney et al. 2019; SánchezBayo and Wyckhuys 2019). At present, more than $40 \%$ of the 6921 native insect species in Central Europa which are

Melanie Marquardt

melanie.marquardt@uni-hohenheim.de

1 Apicultural State Institute, University of Hohenheim, August-von-Hartmann-Str. 13, 70599 Stuttgart, Germany

2 Core Facility Hohenheim and Institute of Economics, University of Hohenheim, Schloss Hohenheim 1C, 70599 Stuttgart, Germany

3 State Horticultural College and Research Institute Heidelberg, Diebsweg 2, 69126 Heidelberg, Germany listed in the IUCN Red List of Threatened Species according to their probability of becoming extinct in a given time period, are currently classified as endangered or even already extinct (Gruttke et al. 2016). This dramatic situation is mainly due to habitat loss or habitat fragmentation (Winfree et al. 2009; Potts et al. 2010; Goulson et al. 2015). The main drivers for this current loss or fragmentation of natural habitats are considered to be intensified agricultural activities and increasing urban developments (Maxwell et al. 2016). There is a broad consensus in the scientific literature on the impacts of intensive agriculture on insect communities which report unanimously a correlative decline of pollinator species richness with the increasing intensity of agricultural activities (Kremen et al. 2002; Steffan-Dewenter 2003). However, evidence on insect biodiversity in urban areas is still inconclusive, despite the rapidly growing literature investigating the effects of urbanization on the local pollinator communities (Wenzel et al. 2020).

Urbanization, the expansion of urban and suburban areas, is a worldwide phenomenon and it is very likely to increase 
globally in the near future (United Nations 2014). The construction of roads, buildings and industrial areas leads to extensive and persistent sealing of landscape, usually at the expense of rural, natural and semi-natural habitats (McKinney 2006). As a result, urbanization is assumed to have negative effects on the availability of food sources, nesting sites and nesting materials of insects which will most likely result in a shift in the species composition or at worst in a loss of biodiversity (Goulson et al. 2015). Consistent with these claims found some previously published studies a negative correlation of insect species richness with the level of urbanization (McIntyre and Hostetler 2001; Matteson et al. 2008; Ahrné et al. 2009; Hernandez et al. 2009; Bates et al. 2011, 2014). However, very recent research suggested contrastingly that urban landscapes can constitute a suitable habitat for pollinators (Hall et al. 2016; Baldock et al. 2019). Some authors even described a positive correlation of urbanization and biodiversity (Lowenstein et al. 2014; Baldock et al. 2015; Theodorou et al. 2017). This finding might be explained by higher flowering plant diversities in highly populated areas (Lowenstein et al. 2014; Theodorou et al. 2017).

Previous literature also reported about major differences in the way insect pollinator groups responded to urbanization. Solitary bees, Diptera, Lepidoptera and Coleoptera were generally highly sensitive to increasing urbanization, whereas bumblebees and honeybees were found at a constant rate across an urban gradient (Bergerot et al. 2011; Hennig and Ghazoul 2011; Mulieri et al. 2011; Geslin et al. 2013; Verboven et al. 2014; Theodorou et al. 2020). It is widely acknowledged that besides the landscape variable, numerous further factors can have a significant impact on the local urban pollinator biodiversity as well. These impact factors may include: landscape characteristics, resource patch size, nesting possibilities, competitors and floral (= nutritional) resources (McIntyre and Hostetler 2001; McFrederick and LeBuhn 2006; Wojcik and McBride 2012; Matteson et al. 2013). However, it is unclear for the most part to what extent these impact factors influence the presence and abundance of insect pollinators.

It is becoming increasingly recognized, that wellmanaged urban parks and other public green urban areas are highly valuable for insect pollinators (McFrederick and LeBuhn 2006; Frankie et al. 2009; Shwartz et al. 2013; Banaszak-Cibicka et al. 2018; Theodorou et al. 2020). There is also clear evidence that privately owned garden properties like allotments and domestic gardens can support a considerable diversity of pollinators (Ahrné et al. 2009; Foster et al. 2017; Baldock et al. 2019). Both, public parks as well as privately owned gardens, generally contain high plant species richness of native, exotic and ornamental plants, thus providing a large potential food resource for pollinators (Hope et al. 2003; Frankie et al. 2005; Hülsmann et al. 2015; Lowenstein et al. 2019).
Ornamental plants are available in a huge variety and in urban areas, they are popular as garden plants and are very frequently planted (Loram et al. 2008). Whether the use of ornamental plants is contributing to the local pollinator biodiversity, however, is currently still under debate. At the same time, the number of studies investigating the value of ornamental plants for pollinating insects is increasing rapidly (e. g. Garbuzov and Ratnieks 2014; Garbuzov et al. 2017; Lowenstein et al. 2019; Rollings and Goulson 2019; Erickson et al. 2020). These studies indicated that many ornamental plants can represent an important, additional nectar and pollen food source for pollinators. However, they also concluded, that the attractiveness of ornamental plants varied strongly (Garbuzov and Ratnieks 2014, 2015; Erickson et al. 2020). Based on these results, Rollings and Goulson (2019) suggested to continue investigating the value of further ornamental plant species and cultivars for pollinators, preferably at various sites with different environmental conditions (Rollings and Goulson 2019).

Given the current knowledge, there is clearly a strong need for testing ornamental plants in regard to their pollinator friendliness. With this study, we aim to contribute further empirical evidence on the plant species and cultivars which have been approved to be beneficial for pollinators. For this purpose, we used a selection of 28 ornamental plant cultivars and quantified the foraging insects. In particular, we wanted to compare the number of insect visitors observed on the different ornamental plant species and cultivars. As only a small number of studies investigated the role of ornamental plants in urbanized areas, this was also a field of interest for us to work on. Furthermore, we evaluated whether the location or the study year had a significant impact on the results. To achieve this, the present study was carried out in urban and suburban areas in Stuttgart, a large city in Southern Germany. Over a two-year period (2017-2018) the foraging activities of different groups of pollinators at 13 urban testing areas which were planted with an identical set of ornamental plants were observed.

\section{Material \& methods}

\section{Locations of the testing areas}

This study was conducted within the city area of Stuttgart (Southwest of Germany; area $208 \mathrm{~km}^{2}$; population 630,000) using 13 different locations which were unevenly distributed over the city (Fig. 1). In order to be considered as a suitable location for our study, the locations needed to fulfill the following two conditions: (1) free access, and (2) free space to install a raised flower bed. Based on these requirements, the study sites were selected randomly and included urbanized areas as well as suburban regions. Consequently, the 


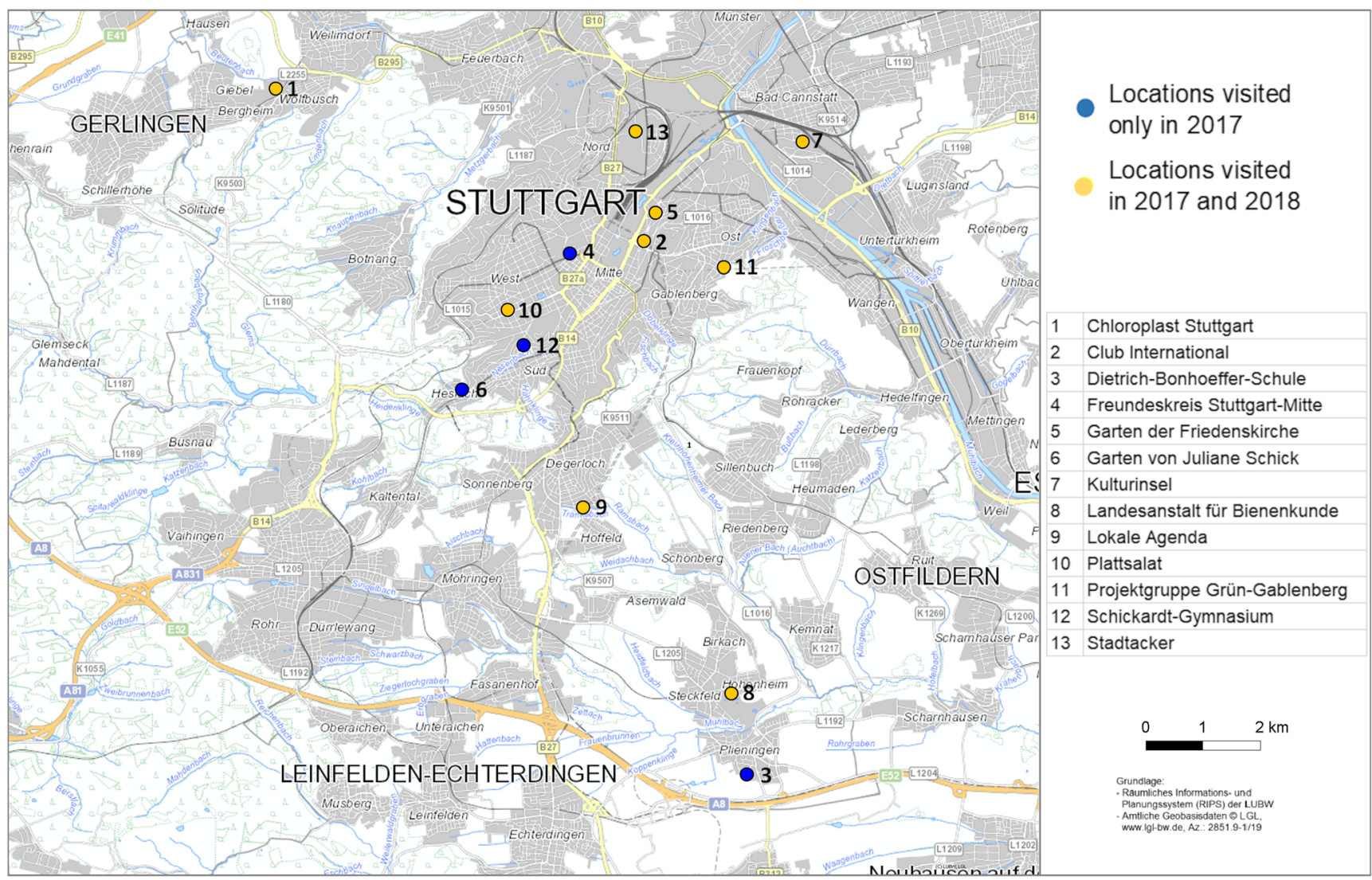

Fig. 1 Map of the city of Stuttgart. The 13 locations of the testing sites are depictured by dots (blue $=$ locations that were only visited in 2017, yellow $=$ locations that were visited in 2017 and 2018) and numbers. The corresponding names can be found in the associated list. Figure 1

surroundings varied greatly within the different testing areas in the percentage of impervious surfaces (Table 1).

Table 1 Further parameters of the 13 locations of the testing areas in this study. The classification of the location (urban or suburban) was determined by the geographical position and the surrounding was exported from UDO (Geodata services Baden-Württemberg; Copyright: Geobasisdaten OLGL, www.lgl-bw.de) and edited in GIMP 2.10 .18

In the year 2017, all 13 testing sites were provided with one raised flower bed with an area of one $\mathrm{m}^{2}$ made up of three to

environment of the testing areas. The percentages of impervious surface of the locations were calculated with the help of ArcGIS 10.6

\begin{tabular}{|c|c|c|c|c|c|}
\hline \# & Name of the location & $\begin{array}{l}\text { Classification } \\
\text { of the location }\end{array}$ & $\begin{array}{l}\text { Impervious surface } \\
\text { in } 250 \mathrm{~m} \text { radius [\%] }\end{array}$ & $\begin{array}{l}\text { Impervious surface } \\
\text { in } 500 \mathrm{~m} \text { radius [\%] }\end{array}$ & Coordinates \\
\hline 1 & Chloroplast Stuttgart & Suburban & 65.6 & 50.6 & $48.805694^{\circ} \mathrm{N}, 9.101854^{\circ} \mathrm{E}$ \\
\hline 2 & Club International & Urban & 94.9 & 82.0 & $48.779073^{\circ} \mathrm{N}, 9.187675^{\circ} \mathrm{E}$ \\
\hline 3 & Dietrich-Bonhoeffer-Schule & Suburban & 51.1 & 47.0 & $48.697712^{\circ} \mathrm{N}, 9.212692^{\circ} \mathrm{E}$ \\
\hline 4 & Freundeskreis Stuttgart-Mitte & Urban & 67.5 & 87.0 & $48.780483^{\circ} \mathrm{N}, 9.170923^{\circ} \mathrm{E}$ \\
\hline 5 & Garten der Friedenskirche & Urban & 94.7 & 78.1 & $48.786018^{\circ} \mathrm{N}, 9.192164^{\circ} \mathrm{N}$ \\
\hline 6 & Garten von Juliane Schick & Suburban & 89.7 & 56.6 & $48.757739^{\circ} \mathrm{N}, 9^{9} 146063^{\circ} \mathrm{E}$ \\
\hline 7 & Kulturinsel & Urban & 94.2 & 93.5 & $48.797109^{\circ} \mathrm{N}, 9.226981^{\circ} \mathrm{E}$ \\
\hline 8 & Landesanstalt für Bienenkunde & Suburban & 37.7 & 55.2 & $48.709224^{\circ} \mathrm{N}, 9.210376^{\circ} \mathrm{E}$ \\
\hline 9 & Lokale Agenda & Suburban & 44.5 & 66.3 & $48.739607^{\circ} \mathrm{N}, 9.171090^{\circ} \mathrm{E}$ \\
\hline 10 & Plattsalat & Urban & 99.2 & 95.1 & $48.770854^{\circ} \mathrm{N}, 9.156868^{\circ} \mathrm{E}$ \\
\hline 11 & Projektgruppe Grün-Gablenberg & Suburban & 64.0 & 61.9 & $48.777366^{\circ} \mathrm{N}, 9.208367^{\circ} \mathrm{E}$ \\
\hline 12 & Schickardt-Gymnasium & Urban & 99.9 & 95.1 & $48.764934^{\circ} \mathrm{N}, 9.160181^{\circ} \mathrm{E}$ \\
\hline 13 & Stadtacker & Urban & 71.0 & 73.1 & $48.798823^{\circ} \mathrm{N}, 9.187421^{\circ} \mathrm{E}$ \\
\hline
\end{tabular}


four pallet frames that were stacked onto each other. As filling materials, branches and stones were used and to obtain a standardized top layer of approximately $30 \mathrm{~cm}$ height, four $80 \mathrm{~L}$ bags of commonly used potted soil (Einheitserde Primel \& Viola (Patzer), medium texture (Sodentorf) with $1 \mathrm{~kg}$ PGMix and $1 \mathrm{~kg}$ Gepac) were applied. Due to organizational reasons, the number of testing sites was reduced to 9 in the year 2018. The four testing sites that were visited only in 2017 were: Dietrich-Bonhoeffer-Schule (3), Freundeskreis Stuttgart-Mitte (4), Garten von Juliane Schick (6) and Schickardt-Gymnasium (12).

\section{Testing plants}

A total of 28 ornamental garden plants that included 14 species and hybrids, all being exotic to Germany, were tested (Table 2). Exotic or non-native plants are defined as plants which are foreign to the German ecosystems and do not naturally occur there. Usually, exotic plants have been introduced by anthropogenic interventions (Hettinger 2001; Pyšek et al. 2004). This assortment of plants was chosen as (I) the particular species have proven to be visited by pollinators for foraging reasons in a previously conducted study by our workgroup (Kretschmer 2016), (II) these species are known to grow well in Central Europe and (III) they are popular as ornamental garden plants in Germany and therefore widely and easily to purchase in garden centers.

All plants were cultivated without a pesticide treatment, neither synthetic nor organic, but natural enemies against aphids and thrips were applied. Each of the raised flower beds was planted with the exact same assortment of cultivars, but the planted arrangement of the cultivars varied within the different locations. The arrangements were designated beforehand and the plants were subsequently planted in accordance with the outcome of the randomization. Figure 2 shows the exemplary planting at the location Projektgruppe Grün-Gablenberg in the year 2017.

In the first study year, all flower beds were planted by end of May. Although many cultivars are known to be perennial or half-hardy, all flower beds were replanted by the end of May in 2018. This was done for the two following reasons: (I) a de novo planting ensured an even and comparable flower production within the different locations and (II) due to organizational reasons, the assortment of tested plant cultivars needed to be adjusted and reduced in the second study year. Generally, the flower beds were watered manually once or twice a week. The number of irrigations, however, depended highly on the local weather conditions and consequently varied within the locations and in the course of the study. All flower beds were freed from unwanted and not embedded plants (weeds). Further plant care, such as fertilization or cutting back, were not conducted.

\section{Data collection}

Data were collected in the years 2017 and 2018. In the year 2017, all 13 flower beds were visited 9 times from 01 June to 23 August 2017. In the year 2018, the remaining 9 flower beds were visited 10 times from 19 June to 28 August 2018. All flower beds were visited between 10:00-17:00 and the observations were made only on favorable weather, i.e. on days with a minimum peak daytime temperature of $20^{\circ} \mathrm{C}$, with low wind and full to partial sun. The observations were done in a random order (day and time) but generally, each flower bed was visited once a week. At every visit, the current weather condition and the floral abundance for each cultivar was recorded. For the recording of the floral abundance, we adapted the method from two already established protocols (Baldock et al. 2015; Lowenstein et al. 2019). However, we slightly modified it in order to make it more appropriate for our methodological set-up and selection of testing plants. In the following, we refer to the term flowering unit, which comprised of a single flower or a capitulum. Rather than treating inflorescences and floral clusters as one single unit, we counted the single flowers separately, as long as they could be perceived as one complete and independent unit. The numbers of flowering units were counted precisely.

For the observations, all raised flower beds were monitored for $20 \mathrm{~min}$ and the number of flower-visiting insects was recorded for each cultivar. A flower visit was only counted, if the insect was observed to be actively collecting pollen and/or nectar or coming in contact with the reproductive structure of the tested plant (see Lowenstein et al. 2019; Erickson et al. 2020). After being counted, the pollinators were not removed from the testing areas but stayed in-field. Therefore, it is possible that pollinators might have been counted multiple times during the 20-min observations. The observed insects were classified into the following five groups: Honeybees (Apis mellifera L.), bumblebees (Bombus spp.), other wild bees (non-Apis and non-Bombus), hoverflies (Diptera: Syrphidae) and other pollinating insects (flies, wasps, beetles, butterflies and moths), as they could easily be categorized in these broad functional groups in the field.

\section{Statistical analyses}

Data were analyzed using an ANOVA-type generalized linear mixed model (GLMM) based on the restricted maximum likelihood (REML) method using R 3.6.2 (R Core Team 2019) and the package ASReml-R (Butler 2020). Based on the residual and Q-Q-plot, a poisson distribution using the natural log-transformation was chosen for the GLMM which is quite typical for such count data. In addition to the count data of the different pollinator groups, the GLMM was also applied on species richness. For the latter, the Shannon diversity index was calculated using the $\mathrm{R}$ package vegan (Oksanen et al. 
Table 2 List of the plant species and cultivars tested in this study. The detailed list is in an alphabetical and chronological order

\begin{tabular}{|c|c|c|c|c|c|c|}
\hline$\#$ & Species & Cultivar & Common Name & Supplier & Plant Category & Test year \\
\hline 1 & Bidens ssp. & 'Firelight Exp.' & Marigold & Kientzler & Annual & 2017 \\
\hline 2 & Bidens ssp. & 'Moonlight Exp.' & Marigold & Kientzler & Annual & 2017 \\
\hline 3 & Bidens ssp. & 'Starlight' & Marigold & Kientzler & Annual & 2018 \\
\hline 4 & Bracteantha bracteata & 'Mohave Yellow' & Strawflower & Selecta One & Annual & 2018 \\
\hline 5 & Cleome hassleriana & 'Señorita Rosalita' & Spider Flower & Kientzler & Annual & 2017,2018 \\
\hline 6 & Coreopsis grandiflora & 'Solanna Glow' & Tickseed & Florensis & Perennial & 2017 \\
\hline 7 & Coreopsis ssp. & 'Ka-pow Cream' & Tickseed & Moerheim & Perennial & 2017 \\
\hline 8 & Coreopsis ssp. & 'Ka-pow Dark Red' & Tickseed & Moerheim & Perennial & 2017 \\
\hline 9 & Coreopsis ssp. & 'Mango Punch' & Tickseed & Kientzler & Perennial & 2018 \\
\hline 10 & Coreopsis ssp. & ‘Pink Lady’ & Tickseed & Kientzler & Perennial & 2018 \\
\hline 11 & Coreopsis ssp. & 'Sangria' & Tickseed & Kientzler & Perennial & 2018 \\
\hline 12 & Dahlia $x$ hortensis & 'Dahlegria Red-Yellow' & Dahlia & Florensis & Perennial & 2017 \\
\hline 13 & Dahlia $x$ hortensis & 'Labella Medio Pink’ & Dahlia & Beekenkamp & Perennial & 2017 \\
\hline 14 & Dahlia $x$ hortensis & 'Dahlegria Red-Pink' & Dahlia & Florensis & Perennial & 2017,2018 \\
\hline 15 & Dahlia $x$ hortensis & 'Krishna' & Dahlia & Selecta One & Perennial & 2018 \\
\hline 16 & Erigeron karvinskianus & 'Blütenmeer' & Karwinsky's Fleabane & Staudenrausch & Perennial & 2017 \\
\hline 17 & Euphorbia hypericifolia & 'Snow Valley' & Graceful Spurge & Volmary & Annual & 2017 \\
\hline 18 & Euphorbia hypericifolia & 'Diamond Frost' & Graceful Spurge & Kientzler & Annual & 2017,2018 \\
\hline 19 & Gaura lindheimeri & 'Gambit Rose' & Lindheimer's Beeblossom & Volrmary & Perennial & 2017 \\
\hline 20 & Gaura lindheimeri & 'Snowbird' & Lindheimer's Beeblossom & Kientzler & Perennial & 2017 \\
\hline 21 & Gaura lindheimeri & 'Belleza White '14' & Lindheimer's Beeblossom & Selecta One & Perennial & 2018 \\
\hline 22 & Heliotropium arborescens & 'Marino Blue' & Common Heliotrope & Kientzler & Half-hardy & 2017 \\
\hline 22 & Heliotropium arborescens & 'Marino Blue' & Common Heliotrope & Selecta One & Half-hardy & 2018 \\
\hline 23 & Lavandula angustifolia & 'LesBleus Thierry' & True Lavender & Selecta One & Half-hardy & 2018 \\
\hline 24 & Salvia farinacea & 'Light Candle' & Mealycup Sage & Kienzler & Perennial & 2017 \\
\hline 25 & Salvia farinacea & 'White Candle' & Mealycup Sage & Kientzler & Perennial & 2017 \\
\hline 26 & Salvia farinacea & 'Farina Blue' & Mealycup Sage & Volmary & Perennial & 2017,2018 \\
\hline 27 & Scabiosa columbaria & 'Mariposa Blue' & Pigeon's Scabious & Florensis & Perennial & 2018 \\
\hline 28 & Scaevola aemula & 'Surdiva Pink Blue' & Fan Flower & Volmary & Perennial & 2017,2018 \\
\hline
\end{tabular}

2019). The model was set up as one model for 7 response variables (total insect number, honeybee number, bumblebee number, other wild bee number, hoverflies number, other pollinator number and Shannon Diversity index) to enable precise comparisons of the effects of the explanatory variables. The fitted model resulting from Akaike's Information Criterion (AIC) model selection was as follows, here denoted in the standard notation:

$$
\begin{aligned}
y_{i j}= & \mu+c_{i}+s_{j}+(s v)_{j k}+f_{l}+(s f)_{j l}+o_{m}+(c s o)_{i j m} \\
& +(c v o)_{i k m}+(c d)_{i n}
\end{aligned}
$$

where $\mu$ general effect

$$
\begin{array}{ll}
c_{i} & \text { effect of the } i \text {-th year } \\
s_{j} & \text { effect of the } j \text {-th species }
\end{array}
$$

$(s v)_{j k} \quad$ nested effect of the $k$-th cultivar within the $j$-th species

$f_{l} \quad$ effect of the flowering unit

$(s f)_{j l} \quad$ interaction effect between the $j$-th species and the flowering unit

$o_{m} \quad$ effect of the $m$-th location

$(c s o)_{i j m} \quad$ interaction effect between the $i$-th year, the $j$-th species and the $m$-th location $(c v o)_{i k m}$ interaction effect between the $i$-th year, the $k$-th cultivar and the $m$-th location $(c d)_{\text {in }} \quad$ nested effect of the $n$-th observational day within the $i$-th year

The effect of the year, plant species and cultivar nested within the plant species were taken as fixed effects because they represented a fix set of factor levels to be tested. Fixed effects can be tested for significance, so a significant effect would mean that given the underlying data, there is evidence 
Fig. 2 Photograph shows the raised flower bed on the location Projektgruppe Grün-Gablenberg in the year 2017. This photograph was taken on the 22 August 2017. Figure 2 was edited in GIMP 2.10 .18

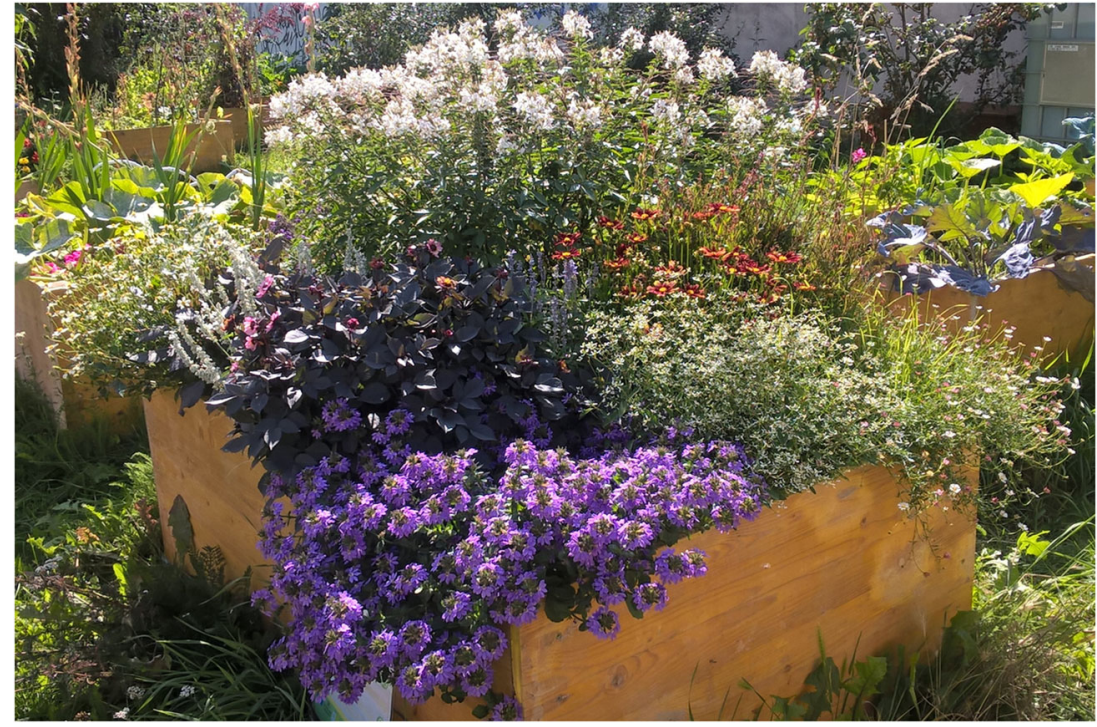

that this term affects the corresponding response variable. The flowering unit was taken as a covariate to adjust for the different numbers of open flowers, so it was considered as a random effect. The effects of the location and the observational day within the year were modelled as random effects because they represent a random sample from the target environments/days of the time span. All interaction effects were also modelled as random since at least one of their incorporated effects is a random effect. An interaction effect which explains a substantial amount of variance would mean that the factor levels of its main effects interact with each other and can therefore only be interpreted in this interaction relation. As the percentage of impervious area in 250/500 m around the testing areas, the classification of location in urban and suburban and the days nested within the years did not explain the model any further, these variables were omitted from the analysis. For the variance components, all model effects were taken as random. Post hoc pairwise comparisons of the location, plant species and cultivars were performed using the Least Squares Means Test in SAS (SAS 9.4).

Further, correlations between the count data of the response variables (total number of pollinators, honeybees, bumblebees, wild bees, hoverflies and others) and the flowering unit were conducted using the Spearman's rank-order correlation (Spearman 1906) because of the non-linearity of the data.

Redundancy Analysis ordination (RDA) was carried out to determine if the pollinator communities were truly different between the study years, among the plant species and cultivars as well as the locations. These analyses were also conducted in R 3.6.2 (R Core Team 2019) using the package vegan (Oksanen et al. 2019). The explanatory variables were tested separately and we conducted two RDAs for (I) the location and (II) the year, plant species and cultivar. Performing one large RDA with all variables yielded qualitatively similar results, but was more difficult to interpret.

\section{Results}

\section{Abundance of pollinators and composition of the pollinator communities}

In both years, the most common pollinator group was the bees with $89-94 \%$ (Fig. 3a-b). This group comprised of $54-55 \%$ wild bees, 23-30\% honeybees and 4-17\% bumblebees. Hoverflies were 3-8\% and other pollinators made up $3 \%$. The relative abundance of the pollinator groups was almost similar in both years, except for the honeybees and bumblebees. The honeybees were more frequently observed in the year 2017 than in 2018 (30\% and $23 \%$ respectively) but it was the opposite for the bumblebees (4\% in 2017 and $17 \%$ in 2018).

Besides the relative abundance, the absolute numbers were also variable within the study years. Across the two observation years, a total of 10,565 pollinators were counted. In the year 2017, 5776 pollinators and in the year 20184789 pollinators were observed. We found the absolute abundance of all pollinator insects to be significantly different in the years 2017 and 2018 (Wald test: $D f=1$, Wald statistic $=3.133$, $P<0.001)$. This suggests that the local pollinator composition was highly dependent on the year.

\section{Number of pollinators and pollinator composition at the different locations}

The mean number of recorded pollinators varied among the 13 different testing sites (Supporting Information Fig. S1). At Chloroplast Stuttgart, the highest total amount of 5.0 visitors in average was observed, followed by the Projektgruppe Grün-Gablenberg with a mean of 4.4 visitors. At the location Kulturinsel the lowest amount in average was recorded with 1.6 visitors. The composition of the pollinator groups varied 
(a) 2017

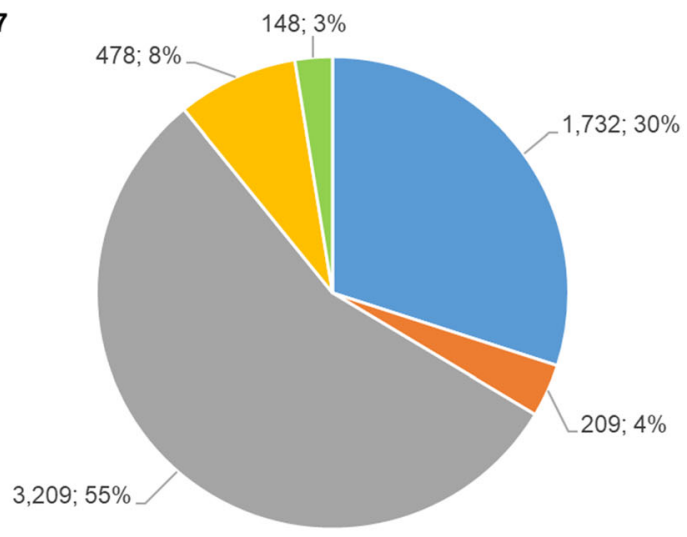

(b) 2018

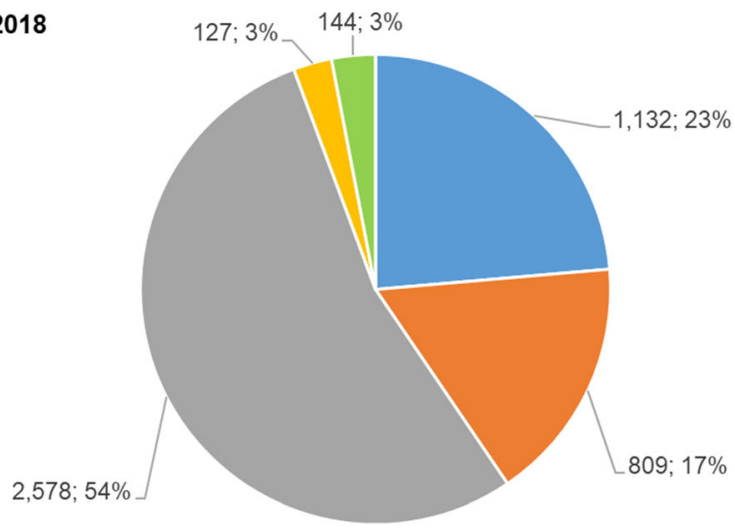

- Honeybees " Bumblebees "Other wild bees " Hoverflies "Others

Fig. 3 Relative and absolute abundance of the recorded pollinators in the year 2017 (a) and 2018 (b). Figure 3 was created in Microsoft Excel (Office 2019) and edited in GIMP 2.10.18

within the 13 different locations as well: The honeybees occurred with a range of $9.1-58.1 \%$, bumblebees $0.8-23.2 \%$, other wild bees 33.9-69.9\%, hoverflies 1.4-18.3\% and others $0.6-6.0 \%$ within the different locations. The amount and composition of the pollinators revealed highly significant differences among the 13 testing locations (GLMM: $\mathrm{Df}=12, F=$ $4.82, P<0.001)$, emphasizing the huge impact of the location on the pollinator communities.

The abundance and composition of the insect pollinator groups was further examined using Redundancy Analysis (RDA) with the location being the explanatory variable (Fig. 4). The displayed axes together explained $5.1 \%$ of the variation in the local insect pollinator communities. The analysis revealed that the variable location was highly significant (Df $=12, F=17.037, P<0.001)$. However, only three of the pollinator groups that were observed in this study showed a clear relationship to the locations: Honeybees, bumblebees and other wild bees. The two remaining pollinator groups hoverflies and other pollinating insects were closely located to the center point of the RDA, showing no relationship to the locations. The bumblebee abundance was closely connected with the three locations Projektgruppe Grün-Gablenberg, Plattsalat and Garten von Juliane Schick. The other wild bees were also present in the mentioned three locations, but the connection was considerably lower. The three locations Chloroplast Stuttgart, Landesanstalt für Bienenkunde and Schickardt-Gymnasium were mainly characterized by the occurrence/absence of honeybees, however, this connection was rather low.

\section{Pollinator abundance and composition on the tested plant species and cultivars}

Pollinators were seen visiting and foraging on all tested plant species. However, the tested plant species showed an up to 5fold variation in their number of pollinators flower visitors (Supporting Information Fig. S2). For both years, the plants with the highest number of flower-visiting insects were Bidens ssp. (5.3 mean visitors), Coreopsis ssp. (4.1 visitors) and Euphorbia hypericifolia (3.8 visitors). Heliotropium arborescens and Bracteantha bracteata were among the least visited species (1.6 and 1.2 mean pollinators respectively). In both years, the pollinators showed group-specific preferences. E. hypericifolia-pollinators comprised of more than $80 \%$ of wild bees. Bidens ssp. and Coreopsis ssp. were often visited by honeybees, while Lavandula angustifolia and Scabiosa columbaria were predominately visited by bumblebees. The results suggest that the plant species had a significant effect on the pollinator abundance and composition in all pollinator groups (Wald test: $D f=12$, Wald statistic $=69.888$, $P<0.001)$.

Reviewing the results for the tested cultivars in detail confirmed that besides the plant species, all cultivars were visited by pollinators for collecting either pollen or nectar. However, the number of visitors varied within the cultivars up to 9-fold (Fig. 5). Of all tested cultivars, the highest number of visitors in average were recorded on $B$. ssp. 'Starlight' (8.9 visitors), followed by $C$. ssp. 'Pink Lady' with 8.1 flower-visiting insects. The pollinator abundance was the lowest on B. bracteata 'Mohave Yellow' with 1.3 pollinators. The pollinators also showed group-specific preferences in the cultivars. Dahlia $x$ hortensis 'Krishna' and L. angustifolia 'LesBleus Thierry' were mostly visited by bumblebees, whereas the other wild bees preferred E. hypericifolia 'Diamond Frost' and $C$. ssp. 'Mango Punch'. Hoverflies and other pollinators were extremely rare. We can conclude, that the cultivar was a highly significant factor for the pollinator abundance and composition (Wald test: $D f=15$, Wald statistic $=40.188, P<0.001$ ). The results of the Least Square Means test showed that especially the three cultivars $B$. ssp. 'Starlight', $B$. ssp. 'Firelight Exp.' and $C$. ssp. 'Pink Lady' differed significantly in the amount and composition of the pollinator visitors.

In an RDA with the year, species and cultivar being the explanatory variables, the displayed axes together 
Fig. 4 RDA biplot examining the relationship between the insect pollinator groups and the location of the testing areas (explanatory variable). High vector lengths indicate high relationships, short lengths the lack of it. Figure 4 was created in R 3.6.2 (R Core Team 2019)

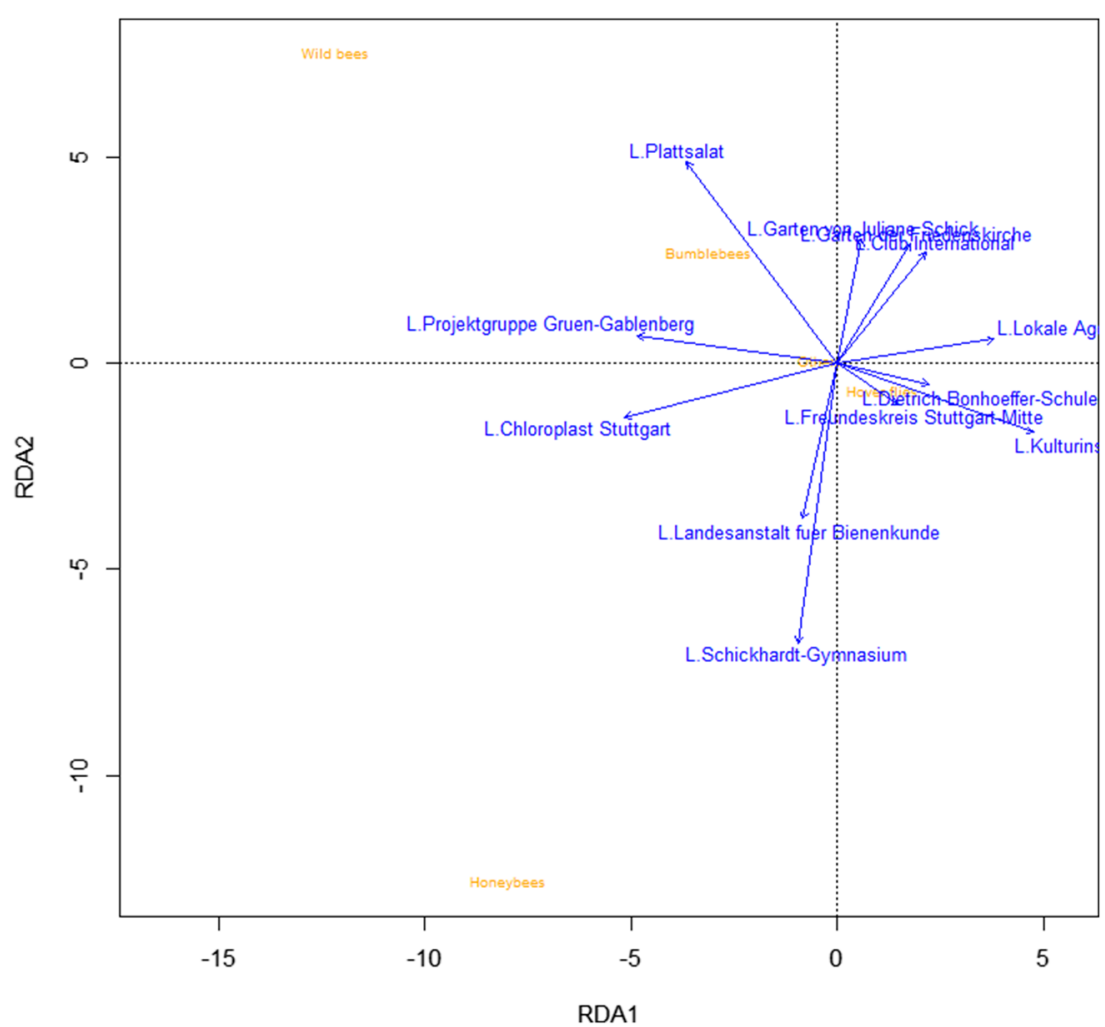

explained $12.4 \%$ of the variation in the observed insect pollinators. All three variables had a significant impact (Year: $\mathrm{Df}=1, F=12.835, P<0.001$; Species: $\mathrm{Df}=12$, $F=11.220, P<0.001$; Cultivar: $\mathrm{Df}=28, F=8.391$, $P<0.001)$. While only the three frequently observed pollinator groups honeybees, bumblebees and other wild bees showed a connection to the tested plant cultivars, a relationship between the hoverflies, other insects to the tested plant cultivars was not noticeable (Fig. 6a-b). Within the honeybees, the relationship was the highest with $B$. ssp. 'Starlight' and $C$. ssp. 'Pink Lady'. Bumblebees were frequently connected to Dahlia $x$ hortensis 'Krishna' and 'Labella Medio Pink' and the other wild bees showed a high relation to $E$. 'Diamond frost'.

\section{Correlations of the flowering units and number of flower visits among the pollinator groups}

We found a highly significant positive correlation between the number of flowering units and the number of all pollinator visits (Spearman's rank correlation: $r=0.53, P<0.001$ ). However, the correlation coefficient varied among the pollinator groups (Supporting Information Fig. S3). The wild bees showed the highest correlation with flowering units $(r=0.46$, $P<0.001)$, followed by honeybees $(r=0.25, P<0.001)$, hoverflies $(r=0.19, P<0.001)$, other pollinators $(r=0.19$, $P<0.001)$ and bumblebees $(r=0.13, P<0.001)$.

\section{Impacts of the tested variables on the pollinator communities and the diversity index}

Using a GLMM, we analyzed the effects of the fixed, random and nested variables on the response variables (all pollinator groups and the Shannon diversity index). The statistical analyses revealed that the impact of the individual variables varied according to the different pollinator groups (Fig. 7). The study year was a decisive factor for the bumblebees (22.9\%) and even more for the other pollinators. For the latter, the variable year explained $54 \%$ of the variance in composition and abundance. It is noticeable that the plant species had the biggest impact on the bumblebees $(18.5 \%)$ and other wild bees $(22.1 \%)$. The location played a considerable role for honeybees $(16.0 \%)$ and hoverflies $(11.2 \%)$. If the plant species and cultivars were nested in other factors (year, location) the influence on the pollinator community were higher compared to the single factor plant species alone. Under the term residual variance, the yet unknown impact factors on the pollinator communities were summed up and ranged from 21.5$35.0 \%$. The percentage shares of the fixed, random and nested variables were also high within the biodiversity index. While the year and the nested variables Year•Location $\bullet$ Species showed a high effect on the Shannon Diversity Index (19.6\% and $11.2 \%$ respectively), the percentage shares of the species and species $\bullet$ cultivar were considerably lower. The nested variable Year $\bullet$ Location $\bullet$ Cultivars did not seem to have an effect at all. However, the residual variance had the 


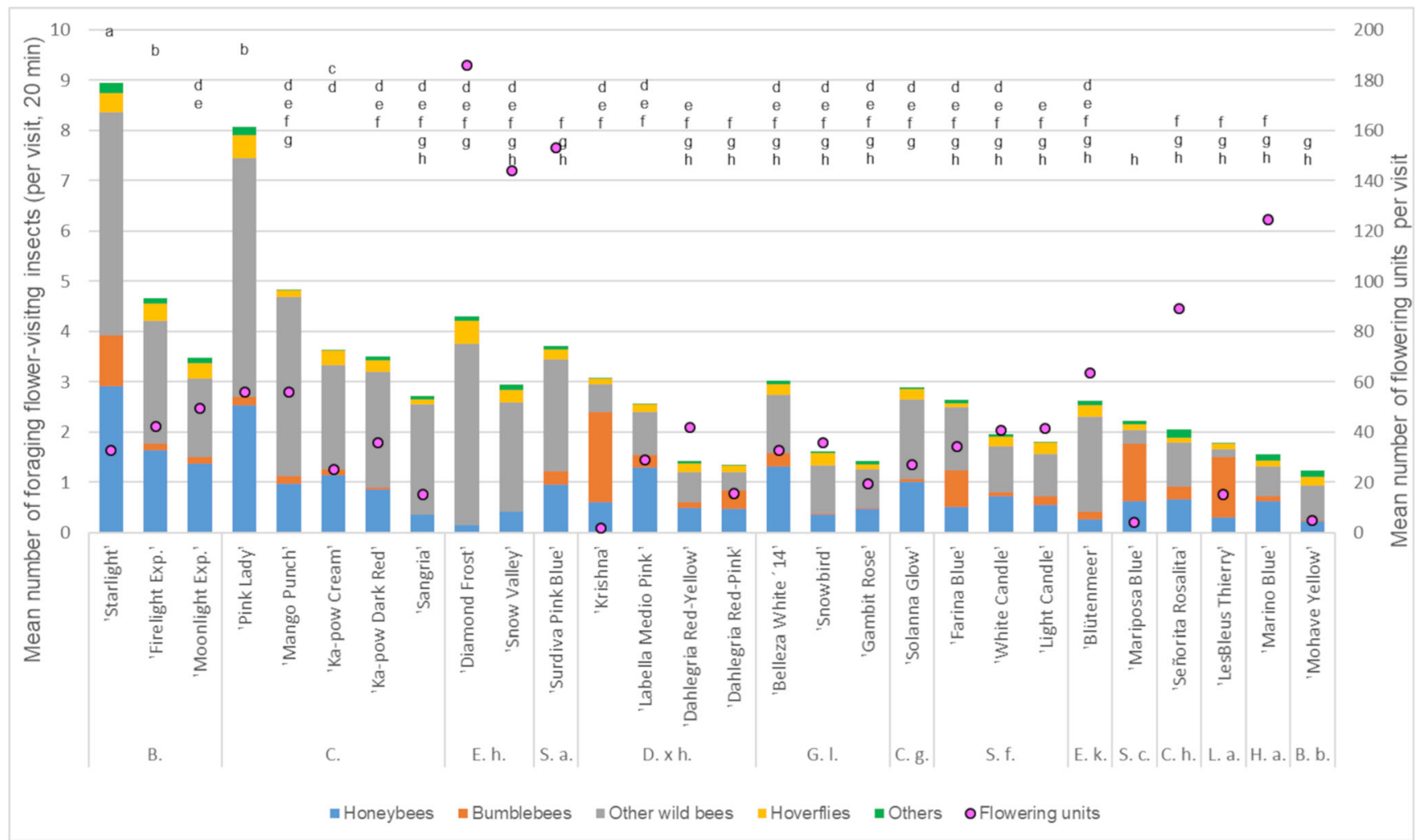

Fig. 5 Mean numbers of flower-visiting insects of all tested cultivars in both years. Letters above the bars represent significant differences based on Least Square Means test, where locations sharing the same letter are not significantly different from each other $(P=0.05)$. Species abbreviations: B. = Bidens ssp., C. = Coreopsis ssp., E. h. = Euphorbia hypericifolia, S. a. = Scaevola aemula, D. $\mathrm{x}$ h. = Dahlia $x$ hortensis, $\mathrm{G}$.
1. = Gaura lindheimeri, C. g. = Coreopsis grandiflora, S. f. = Salvia farinacea, E. k. = Erigeron karvinskianus, S. c. = Scabiosa columbaria, L. a. = Lavandula angustifolia, $\mathrm{H}$. a. = Heliotropium arborescens and B. b. $=$ Bracteantha bracteata . Figure 5 was created in created in Microsoft Excel (Office 2019) and edited in GIMP 2.10.18

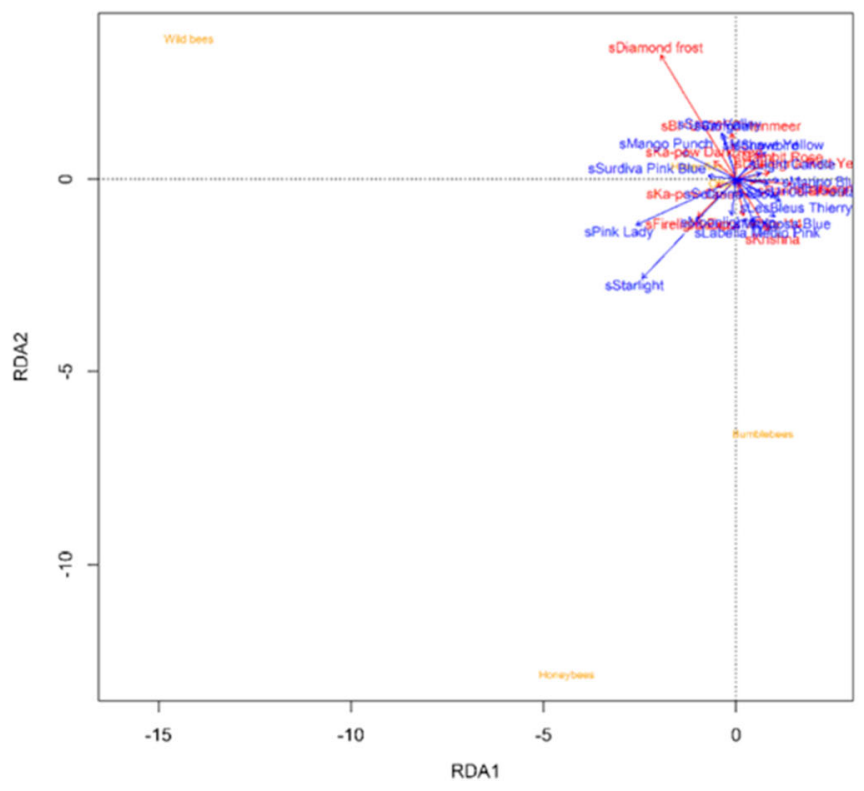

Fig. 6 RDA biplots examining the relationship between the pollinator groups and the explanatory variable cultivar. High vector lengths indicate high relationships, short lengths the lack of it. (a) The left

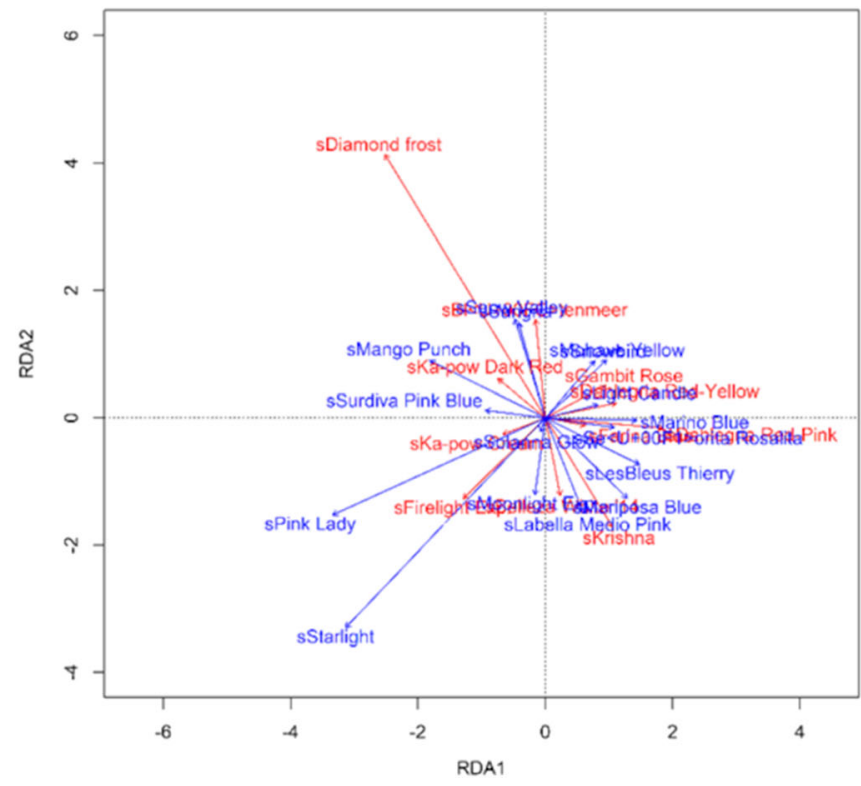

RDA shows the graphical representation in original scaling, (b) shows an excerpt with a lower scaling. Figure 6 was created in R 3.6.2 (R Core Team 2019) and edited in GIMP 2.10.18 
Fig. 7 Proportional effects of the examined variables on the pollinator community based on the GLMM with year, plant species and plant cultivar (nested in species) taken as fixed effects. Figure 7 was created in Microsoft Excel (Office 2019) and edited in GIMP 2.10.18

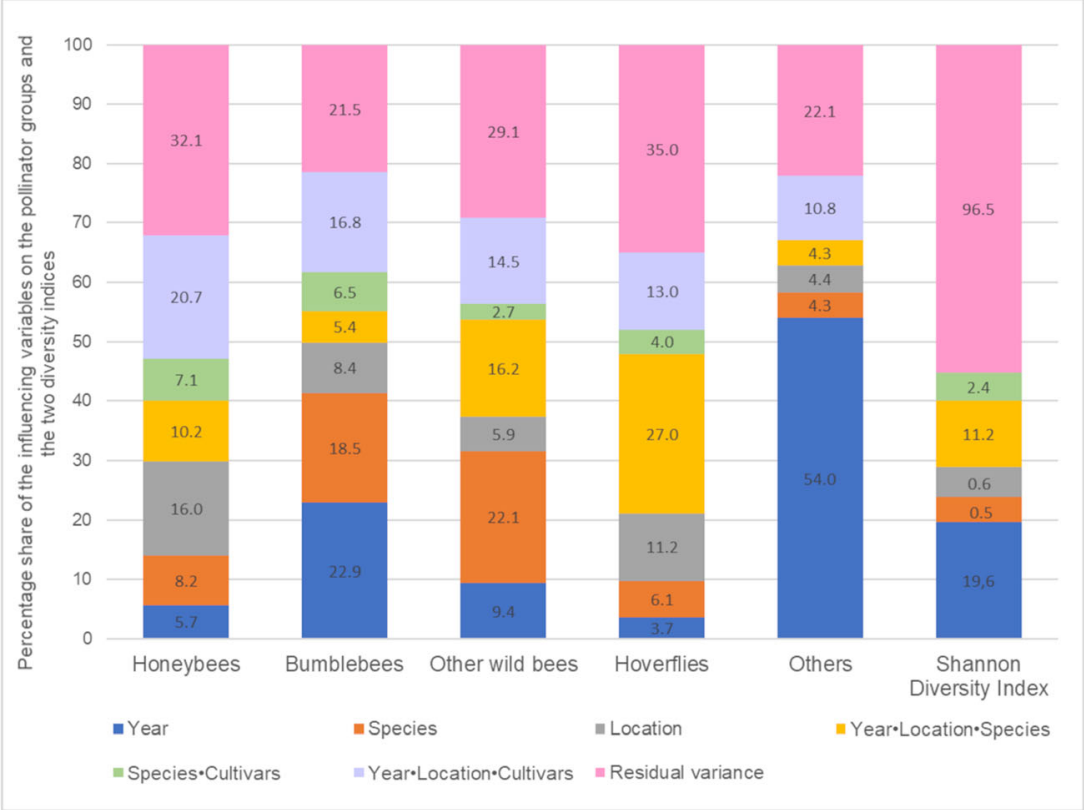

highest impact within the Shannon Diversity Index and amounted 55.3\%.

Analyzing all pollinator groups together, the fixed effects year $(\mathrm{Df}=1$, Wald statistic $=23.671, P<0.001)$, plant species $(\mathrm{Df}=12$, Wald statistic $=69.888, P<0.001)$ and plant species $\bullet$ cultivar $(\mathrm{Df}=15$, Wald statistic $=40.188, P<0.001)$ showed highly significant impacts. Reviewing the results in detail confirmed that the year, plant species and cultivar were either highly significant or significant for all pollinator groups, suggesting that the different pollinator groups were strongly influenced by these fixed effects (Supporting Information Table S1). This is also true for the Shannon Diversity Index (Year: Df $=1$, Wald statistic $=19.907, \quad \mathrm{P}<0.001$, Species: $\mathrm{Df}=12$, Wald statistic $=52.851, \mathrm{P}<0.001$, Species $\bullet$ cultivar: $\mathrm{Df}=15$, Wald statistic $=33.013, \mathrm{P}<0.01$ ).

\section{Discussion}

\section{Responses of the insect pollinators to the offered ornamental plants}

With this two-year study and based on more than 10,000 recorded flower-visiting insects, we find empirical evidence supporting the claim that ornamental plants can have a positive benefit to urban pollinators. All of our tested ornamental plants were visited by individuals of different pollinator groups and we observed them collecting pollen and/or nectar during their flower visits. Based on these observations, we conclude that our assortment of ornamental plants was very likely to be contributing to the nutrition of foraging honeybees, bumblebees, wild bees, hoverflies and other flower- visiting insects in the urban and suburban areas of Stuttgart. However, not all ornamental plant species and cultivars appeared to be equally valuable to the pollinators as the numbers of visiting insects varied up to 5 -fold in the species and up to 9-fold in the cultivars. However, this variation was considerably lower compared to the nearly 100 -fold difference in the number of visitors which was previously reported by Garbuzov and Ratnieks (2014). One probable reason for this difference may lie in the preselection of our tested ornamental plants, as we deliberately chose plant species and cultivars that were considered to be pollinator-friendly which might have led to a lower variation in the number of visitors (see Kretschmer 2016).

The three most frequently visited species in this study were Bidens ssp., Coreopsis ssp. and Euphorbia hypericifolia. To date, published data regarding the pollinator friendliness of these plants are rare. However, one publication rated Bidens ssp. and Coreopsis grandiflora only as 'occasionally visited by honeybees', Coreopsis ssp. as 'moderately visited by honeybees' and E. hypericifolia as 'heavily visited by foraging honeybees' (Cranshaw 2009). These results partly deviate from our observations and this might be explained by the fact that the mentioned publication solely focused on the pollinator honeybee, whereas in our study, all pollinator groups were considered during the observations. Very recently, Scabiosa columbaria, Cleome hassleriana and Dahlia $\mathrm{x}$ hortensis have been tested in another scientific work (Rollings and Goulson 2019). While $S$. columbaria appeared to be highly pollinatorfriendly, the other two species were classified in the lower mid-range regarding the number of pollinator visits (Rollings and Goulson 2019). This result, we could confirm in our study. Within the different cultivars of one species, the 
number of foraging pollinators was also varying. This, however, was highly dependent on the plant species itself. While the variation in the number of visitors was high within the different cultivars in Bidens ssp., Coreopsis ssp., Dahlia x hortensis and Gaura lindheimeri, it was considerably smaller in E. hypericifolia and S. farinaceae. Previous studies came to very similar conclusions (Garbuzov and Ratnieks 2014; Rollings and Goulson 2019; Erickson et al. 2020).

Furthermore, it should be considered that not all pollinator groups foraged in equal parts on our selection of ornamental plants which obviously attracted the bees to a considerable higher extent compared to non-bee pollinators. Within the pollinator group bees, the other wild bees constituted the main pollinators, followed by honeybees and bumblebees. This high number in other wild bee pollinators was not documented in other previous scientific studies before, which also investigated pollinator friendliness in ornamental plants (e. g. Garbuzov and Ratnieks 2014; Garbuzov et al. 2015; Rollings and Goulson 2019). However, they reported of significantly higher numbers in bumblebees, while the percentage shares of honeybees were almost similar (Garbuzov and Ratnieks 2014; Garbuzov et al. 2015). We expect the reason for this being mainly our assortment of ornamental plant species and cultivars and conclude that with this selection of plants especially the urban wild bee abundance can be promoted. During our observations, only a small percentage of flower-visiting insects belonged to hoverflies or other pollinators like butterflies, moths, flies, beetles and wasps. This raised the question whether the selection of ornamental plants was less suitable for these flower-visiting insects or whether these other pollinators were per se less frequent in the urban and suburban environments of Stuttgart. Previous studies indicated that regarding the biodiversity loss, butterflies and moths as well as hoverflies are particularly affected (Biesmeijer et al. 2006; van Dyck et al. 2009; Sánchez-Bayo and Wyckhuys 2019). Therefore, we assume that these groups in general occurred less frequent at the tested locations than the bees. Additionally, it appears that large parts of the ornamental plants are generally scarcely visited by non-bee pollinators like butterflies, moths and hoverflies (see Silva Mouga et al. 2015; Garbuzov and Ratnieks 2014; Rollings and Goulson 2019). Finally, in order to particularly support non-bee pollinators, Shwartz et al. (2013) and Erickson et al. (2020) recommend a careful choice of suitable plants. For example, to support butterflies one should refer to butterfly-friendly plant species like Origanum vulgare, Buddleia davidii or Erysimum bicolor (Shackleton and Ratniecks 2016) or Lantana camara and Zinnia ssp. (Erickson et al. 2020). Diptera might be supported by planting Lobularia maritima (Erickson et al. 2020).

So far, it is poorly understood what is the cause for the variation of pollinators within the cultivars and the preference of particular pollinator groups for specific species in ornamental plants. However, we found clear evidence for a positive correlation of the pollinator numbers and the number of flowering units. This finding is in line with earlier studies (Földesi et al. 2016; Theodorou et al. 2017; Lowenstein et al. 2019). Still, the number of flowering units alone cannot sufficiently explain the obtained results. It is very likely that further floral signals which have not been tested in this study, constituted to the variation and preference in pollinators. It is proven that the quality and quantity of floral reward and the flower accessibility represent further crucial factors for pollinators (Comba et al. 1999; Corbet et al. 2001; Somme et al. 2015). Furthermore, it has been suggested that the environmental context and multiple cultivar-specific floral traits like color, odor and shape drive also pollinator choices (Erickson et al. 2020).

Unfortunately, with this scientific work alone, we cannot evaluate the ecological value of ornamental plants as food sources for insect pollinators completely. To answer this question, a comparison of ornamental (exotic) and native plants would have been necessary (see Salisbury et al. 2015; Lowenstein et al. 2019). However, based on the results obtained in this study and similar to Garbuzov and Ratnieks (2014), we can conclude that with our selection of ornamental plants, it was not possible to support a diverse pollinator community. Pollinator conservation strategies in urban areas differ highly in comparison to the strategies in natural or near-natural environments. In cities, the aim is to increase the overall abundance and diversity of pollinator communities, rather than focusing on rare or endangered species. For this purpose, the use of ornamental plants is certainly adequate (Erickson et al. 2020). In addition, many ornamental plants are bred for high number of flowers, a long flower life and repeated blooming (De 2017) and can therefore fill temporal gaps with limited availability of floral resources. Our selection of ornamental plants flowered continuously from the beginning of June until early October and provided a long, continuous foraging resource for pollinators. In urban areas, where the needs for aesthetics sometimes require the use of ornamental plants over native plants, the best options are long-blooming, rewarding, as well as for pollinator and human attractive ornamental plants (Mach and Potter 2018). Thus, urban pollinator communities might be stabilized (Erickson et al. 2020). However, to enhance the garden's or park's overall value for all flower-visiting insects which also include specialists, endangered species and non-bee pollinators, it is highly recommended to plant a combination of exotic and native plants (Harrison and Winfree 2015; Salisbury et al. 2015).

\section{Influence of the variable location on the pollinator communities}

Our results must be assessed under the aspect that all testing areas were located in urban or suburban areas and these habitat types are generally known to be less favorable environments for pollinators compared to natural habitats (Hernandez et al. 2009; Bates et al. 2011; Geslin et al. 2013). Nevertheless, we 
were able to observe a remarkable number of pollinators during our study and assume that our flower beds, in addition to other local green areas, constituted as valuable habitats in an otherwise hostile urbanized environment. This goes in agreement with some previously published studies (e. g. McFrederick and LeBuhn 2006; Theodorou et al. 2020).

In this study, the abundance of pollinators varied significantly within the 13 tested locations. Another study, in which identical sets of ornamental plants had been tested at two different sites, also reported about site-specific variations in the observed pollinator communities (Erickson et al. 2020; but see Garbuzov and Ratnieks 2014). As possible causes for this, the environmental context and cultivar-specific characteristics were proposed (Erickson et al. 2020). Previous literature indicated that with an increasing degree of urbanization, the abundance and diversity of pollinators decreased and finally, pollinators were found less frequent in highly urbanized areas, compared to suburban or rural areas (McIntyre and Hostetler 2001; Bates et al. 2011; Matteson et al. 2013; Verboven et al. 2014). In order to quantify urbanization, the percentage of impervious area was very often taken as a landscape characteristic variable, which seemed to be one important negative factor in driving the pollinator communities (Ahrné et al. 2009; Matteson and Langellotto 2010; Geslin et al. 2016; Hamblin et al. 2018). While the percentage of impervious surface varied highly within a $250 \mathrm{~m}$ and $500 \mathrm{~m}$ radius surrounding the testing areas at the 13 locations in Stuttgart in our study, we were not able to correlate this in any way with to the number or composition of pollinators. In fact, we did not find any relationship between the classification urban/suburban and the pollinator community.

In addition to the varying numbers of pollinators, we also found the composition of the pollinators to be different within the 13 locations. Again, the obtained variation could not be explained by only the two recorded landscape variables impervious surface and classification urban/suburban. This finding clearly shows the need in recording further local landscape variables in order to explain the obtained results and we recommend future studies to ideally record and incorporate e. g. the variables total garden area, floral area, canopy cover, the presence of wild/unmanaged area and the sunlight availability in their analyses (see Matteson and Langellotto 2010). Additionally, the evaluation of variables which describe the surrounding landscape/habitat in greater detail, e. g. population density could be beneficial. Furthermore, we assume the ranking of the observed foraging pollinators in the five pollinator groups in our study as not being detailed enough for these kinds of statistical analyses and therefore also suggest an identification to genus or even species level in future studies. Although we were not able to explain the observed variation in pollinators within the different locations, we can finally conclude that urbanized areas can indeed represent a suitable habitat for some insect pollinators.

\section{Further impact factors on the pollinators and the diversity index}

Our statistical approach revealed that the year of the survey had a significant impact on the abundance and composition of the pollinators. This was especially true for the bumblebees, other wild bees and other pollinators. Honeybees and hoverflies revealed less differences within the two years. A recently published study from Pennsylvania (USA) reported also of significant variations in the pollinator abundance and composition during the years on ornamental cultivars (Erickson et al. 2020).

It became obvious that besides our so far statistically examined variables (year, location, plant species and cultivar) additional factors influenced the pollinator communities. The statistical model revealed, that within the pollinator assemblages we were only able to explain about $2 / 3$ of the variance. The unidentified rest was simply summed up as residual variance. We assume, that the remaining factors comprised of the surrounding landscape characteristics (habitat quality) as well as the occurrence of dominator species or predators. For future studies, we recommend to pay special attention on these additional variables, as they might help to elucidate the combination of factors with the highest influence on the different pollinator groups. This is also a crucial requirement for management strategies targeting the conservation of pollinators in urban habitats.

When the outcome of the Shannon Diversity Index had been assessed, it became apparent that the tested variables not only showed impacts on the abundance but also on the richness of the pollinator communities. Here, the results indicated, that the tested variables had varying impacts on the pollinator community richness. However, the percentage of residual variance was still quite high. As this is one of the first studies to evaluate the impact factors year, location, tested plant species and cultivar on the pollinator community richness, unfortunately, this aspect of our results cannot be related to existing studies.

\section{Practicability of the standardized method and observations}

Our standardized method which contained raised flower beds and an identical selection of ornamental plants has proven to be very suitable for the analysis of the abundance and composition of pollinators in an urban area. It required only small space and was relatively cost-efficient. With this standardized set-up, it was possible to record and compare the foraging behavior of different pollinator groups on selected ornamental plants at various locations within a large city district. However, as no pollinator was removed after it was counted in our 20-min observations, we cannot exclude the possibility that pseudo-replication might have taken place within the testing plants and locations. This might have led to a slightly increased number of recorded pollinators. Nonetheless, we consider our results as reliable due to the long observation periods and the very large dataset with a 
considerably higher number of recorded flower-visiting insects compared to a similar studies (Garbuzov et al. 2015). By the use of a multivariate statistical model and redundancy analysis we further quantified the combined effects of plant species, cultivar, study year and location on the abundance and composition of pollinators. According to our experience, the method and statistics represented a practicable approach to evaluate the pollinatorfriendliness of ornamental plants while simultaneously assessing the local and annual impacts.

An additional positive side-effect was that all of the testing areas were accessible for the public. Right from the start of the study, we realized an increasing public interest in our study and in questions of bee decline and pollinator protection. Furthermore, many of the sites were located on areas belonging to the Urban Gardening association in Stuttgart and many volunteers helped watering the flower beds during the summer seasons and kept them free from weeds. Therefore, this method provided not only scientific data on urban pollinators. At the same time, it reached and motivated the public to engage for pollinator protection activities and even citizen science projects in urban areas.

\section{Conclusion and recommendation}

This study demonstrated that our tested set of ornamental plants constituted a suitable foraging resource for many pollinators in urban areas. Especially bees and hereby mainly the other wild bees benefited from this additional food source and were observed rather frequently collecting pollen and nectar. However, for hoverflies and other pollinators the ornamental plants seemed to be less suitable. This is one of the first studies providing data on Bidens ssp. and Coreopsis ssp. in regard to their pollinator visitors, which, we both highly recommend for plantings in urban parks, domestic gardens or allotments. Furthermore, we found a high variation in the pollinator numbers in our selection of ornamental plant species and cultivars, indicating differences in the value for the pollinators. Further impact factors on the pollinator abundance and richness were the location and the year. However, a large part of the variance in the pollinator communities remained unexplained by our observed variables. Finally, we conclude that urban and suburban areas can constitute an adequate habitat for pollinators, especially bees, and that many ornamental plants provide a potential foraging resource for pollinators. Conservation strategies in urban areas should include besides a careful choice of plants also location and pollinatordependent approaches.

We generally suggest that new ornamental plant species and cultivars are continuously tested regarding their pollinator-friendliness and that the results are made accessible for the public. The results of the plant species and cultivars we have tested so far, can be reviewed in the Internet: https://lvgsortenfinder.de (for the German-speaking countries).
Supplementary Information The online version contains supplementary material available at https://doi.org/10.1007/s11252-020-01085-0.

Acknowledgments We thank the below-mentioned organizations, schools and private citizens for providing us free space to install the raised flower beds and for allowing us to collect data on their property: Chloroplast Stuttgart e.V., Club International Stuttgart, DietrichBonhoeffer-Schule Stuttgart (Plieningen), Freundeskreis Stuttgart-Mitte, Evangelische Friedenskirche Stuttgart, Juliane Schick, Kulturinsel Stuttgart, Lokale Agenda Stuttgart e.V., Plattsalat e.V., Projektgruppe Grün/Urbanes Gärtnern Gablenberg, Schickardt-Gymnasium Stuttgart and Stadtacker Wagenhallen e.V.. Many thanks to the numerous volunteers who helped watering the plants during the summer time and kept the flower beds free from weed. We also would like to thank the team from the nursery Staudenrausch for providing us the testing plants. MM likes to thank Daniela Warzecha (State Museum of Natural History Karlsruhe) for her help with ArcGIS. Finally, we are grateful for the helpful comments and suggestions from two anonymous reviewers who helped to improve the earlier version of the manuscript.

Authors' contributions UR and PR conceived the research; MM, AP and LAK collected the data; LK, KS and MM analyzed the data; and MM, LK and PR wrote the paper.

Funding Open Access funding enabled and organized by Projekt DEAL. The project was funded by the European Agricultural Fund for Rural Development: Europe investing in rural areas with the participation of the State of Baden-Württemberg.

\section{Compliance with ethical standards}

Conflict of interest The authors declare that they have no conflict of interest.

Open Access This article is licensed under a Creative Commons Attribution 4.0 International License, which permits use, sharing, adaptation, distribution and reproduction in any medium or format, as long as you give appropriate credit to the original author(s) and the source, provide a link to the Creative Commons licence, and indicate if changes were made. The images or other third party material in this article are included in the article's Creative Commons licence, unless indicated otherwise in a credit line to the material. If material is not included in the article's Creative Commons licence and your intended use is not permitted by statutory regulation or exceeds the permitted use, you will need to obtain permission directly from the copyright holder. To view a copy of this licence, visit http://creativecommons.org/licenses/by/4.0/.

\section{References}

Ahrné K, Bengtsson J, Elmgvist T (2009) Bumble bees (Bombus spp) along a gradient of increasing urbanization. PLoS One 4(5):e5574. https://doi.org/10.1371/journal.pone.0005574

Baldock KCR, Goddard MA, Hicks DM, Kunin WE, Mitschunas N, Osgathorpe LM, Potts SG, Robertson KM, Scott AV, Stone GN, Vaughan IP, Memmott J (2015) Where is the UK's pollinator biodiversity? The importance of urban areas for flower-visiting insects. Proc R Soc B 282:20142849. https://doi.org/10.1098/rspb.2014.2849

Baldock KCR, Goddard MA, Hicks DM, Kunin WE, Mitschunas N, Morse H, Osgathorpe LM, Potts SG, Robertson KM, Scott AV, Staniczenko PPA, Stone GN, Vaughan IP, Memmott J (2019) A systems approach reveals urban pollinator hotspots and conservation 
opportunities. Nat Ecol Evol 3:363-373. https://doi.org/10.1038/ s41559-018-0769-y

Banaszak-Cibicka W, Twerd L, Fliszkiewicz M, Giejdasz K, Langowska A (2018) City parks vs. natural areas - is it possible to preserve a natural level of bee richness and abundance in a city park? Urban Ecosyst 21:599-613. https://doi.org/10.1007/s11252-018-0756-8

Barnosky AD, Matzke N, Tomiya S, Wogan GOU, Swartz B, Quental TB, Mashall C, McGuire JL, Lindsey EL, Maguire KC, Mersey B, Ferrer EA (2011) Has the Earth's six mass extinction already arrived? Nature 471:51-57. https://doi.org/10.1038/nature09678

Bates AJ, Sadler JP, Fairbrass AJ, Falk SJ, Hale JD, Matthews TJ (2011) Changing bee and hoverfly pollinator assemblages along an urbanrural gradient. PLoS One 6(8):e23459. https://doi.org/10.1371/ journal.pone.0023459

Bates AJ, Sadler JP, Grundy D, Lowe N, Davis G, Baker D, Bridge M, Freestone R, Gardner D, Gibson C, Hemming R, Howarth S, Orridge S, Shaw M, Tams T, Young H (2014) Garden and landscape-scale correlates of moths of differing conservation status: significant effects of urbanization and habitat diversity. PLoS One 9(1):e86925. https://doi.org/10.1371/journal.pone.0086925

Bergerot B, Fontaine B, Julliard R, Baguette M (2011) Landscape variables impact the structure and composition of butterfly assemblages along an urbanization gradient. Landsc Ecol 26:83-94. https://doi. org/10.1007/s10980-010-9537-3

Biesmeijer JC, Roberts SPM, Reemer M, Ohlemüller R, Edwards M, Peeters T, Schaffers AP, Potts SG, Kleukers R, Thomas CD, Settele J, Kunin WE (2006) Parallel declines in pollinators and insect-pollinated plants in Britain and the Netherlands. Science 313(5787):351-354. https://doi.org/10.1126/science.1127863

Butler D (2020) Asreml: fits the linear mixed model. R package version 4(1):0.130 www.vsni.co.uk

Ceballos G, Ehrlich PR, Dirzo R (2017) Biological annihilation via the ongoing sixth mass extinction signalled by vertebrate population losses and declines. Proc Natl Acad Sci U S A 114(30):60896096. https://doi.org/10.1073/pnas.1704949114

Comba L, Corbet SA, Barron A, Bird A, Collinge S, Miyazaki N, Powell M (1999) Garden flowers: insect visits and the floral reward of horticulturally-modified variants. Ann Bot 83(1):73-86. https:// doi.org/10.1006/anbo.1998.0798

Corbet SA, Bee J, Dasmahapatra K, Gale S, Gorringe E, La Ferla B, Moorhouse T, Trevail A, Van Bergen Y, Vorontsova M (2001) Native or exotic? Double or single? Evaluationg plants for pollinator friendly gardens. Ann Bot 87(2):219-232. https://doi.org/10.1006/ anbo. 2000.1322

Cranshaw W (2009) Relative ranking of ornamental plants to foraging honeybees. Coloadou State University, Fort Collins

De LC (2017) Improvement of ornamental plants - a review. Int J Horti 7(22):180-204. https://doi.org/10.5376/ijh.2017.07.0022

Erickson E, Adam S, Russo L, Wojcik V, Patch HM, Grozinger CM (2020) More than meets the eye? The role of annual ornamental flowers in supporting pollinators. Environ Entomol 49(1):178188. https://doi.org/10.1093/ee/nvz133

Földesi R, Kovács-Hostyánszki A, Körösi Á, Somay L, Elek Z, Markó V, Sárospataki M, Bakos R, Varga Á, Nyisztor K, Báldi A (2016) Relationships between wild bees, hoverflies and pollination success in apple orchards with different landscape contexts. Agric Forest Entomol 18(1):68-75. https://doi.org/10.1111/afe.12135

Foster G, Bennett J, Sparks T (2017) An assessment of bumblebee (Bombus spp) land use and floral preference in UK gardens and allotments cultivated for food. Urban Ecosyst 20:425-434. https:// doi.org/10.1007/s11252-016-0604-7

Frankie GW, Thorp RW, Schindler M, Hernandez J, Ertter B, Rizzardi M (2005) Ecological patterns of bees and their host ornamental flowers in two northern California cities. J Kans Entomol Soc 78(3):227246. https://doi.org/10.2317/0407.08.1
Frankie GW, Thorp RW, Hernandez J, Rizzardi M, Ertter B, Pawekek JC, Witt SL, Schindler M, Coville R, Wojcik VA (2009) Native bees are a rich natural resource in urban California gardens. Calif Agric 63(3):113-120. https://doi.org/10.3733/ca.v063n03p113

Garbuzov M, Ratnieks FLW (2014) Quantifying variation among garden plants in attractiveness to bees and other flower-visiting insects. Funct Ecol 28(2):364-374. https://doi.org/10.1111/1365-2435.12178

Garbuzov M, Ratnieks FLW (2015) Using the British National Collection of Asters to Compare the Attractiveness of 228 Varieties to FlowerVisiting Insects. Environ Entomol 44:638-646

Garbuzov M, Samuelson EEW, Ratnieks FLW (2015) Survey of insect visitation of ornamental flowers in Southover grange garden, Lewes, UK. Insect Sci 22(5):700-705. https://doi.org/10.1111/1744-7917.12162

Garbuzov M, Alton K, Ratnieks FLW (2017) Most ornamental plants on sale in garden centres are unattractive to flower-visiting insects. Peer J 5:e3066. https://doi.org/10.7717/peerj.3066

Geslin B, Gauzens B, Thébault E, Dajoz I (2013) Plant pollinator networks along a gradient of urbanisation. PLoS One 8(5):e63421. https://doi.org/10.1371/journal.pone.0063421

Geslin B, Le Féon V, Folschweiller M, Flacher F, Carmignac D, Motard E, Perret S, Dajoz I (2016) The proportion of impervious surfaces at the landscape scale structures wild bee assemblages in a densely populated region. Ecol Evol 6(18):6599-6615. https://doi.org/10.1002/ece3.2374

Goulson D, Nicholls E, Botías C, Rotheray EL (2015) Bee declines driven by combined stress from parasites, pesticides, and the lack of flowers. Science 347(6229):1255957. https://doi.org/10.1126/science.1255957

Gruttke H, Binot-Hafke M, Balzer S, Haupt H, Hofbauer N, Ludwig G, Matzke-Hajek G, Ries M (2016) Rote Liste gefährdeter Tiere, Pflanzen und Pilze Deutschlands, band 4: Wirbellose Tiere (Teil 2). Bundesamt für Naturschutz, Bonn-Bad Godesberg, Münster

Hall DM, Camilo GR, Tonietto RK, Ollerton J, Ahrné K, Arduser M, Ascher JS, Baldock KCR, Fowler R, Frankie G, Goulson D, Gunnarsson B, Hanley ME, Jackson JI, Langellotto G, Lowenstein D, Minor ES, Philpott SM, Potts SG, Sirohi MH, Spevak EM, Stone GN, Threlfall CG (2016) The city as a refuge for insect pollinators. Conserv Biol 31(1):24-29. https://doi.org/10.1111/cobi.12840

Hallmann CA, Sorg M, Jongejans E, Siepel H, Hofland N, Schwan H, Stenmans W, Müller A, Sumser H, Hörren T, Goulson D, de Kroon $\mathrm{H}$ (2017) More than 75 percent decline over 27 years in total flying insect biomass in protected areas. PLoS One 12(10):e0185809. https://doi.org/10.1371/journal.pone.0185809

Hamblin AL, Youngsteadt E, Frank SD (2018) Wild bee abundance declines with urban warming, regardless of floral density. Urban Ecosyst 21:419-429. https://doi.org/10.1007/s11252-018-0731-4

Harrison T, Winfree R (2015) Urban drivers of plant-pollinator interactions. Funct Ecol 29(7):879-888. https://doi.org/10.1111/13652435.12486

Hennig EI, Ghazoul J (2011) Plant-pollinator interactions within the urban environment. Perspect Plant Ecol Evol Syst 13(2):137-150. https://doi.org/10.1016/j.ppees.2011.03.003

Hernandez JL, Frankie GW, Thorp RW (2009) Ecology of urban bees: a review of current knowledge and directions for future study. Cities and the Environment (CATE) 2(1):3-15 [online] URL: https:// digitalcommons.lmu.edu/cate/vol2/iss $1 / 3$

Hettinger N (2001) Defining and evaluating exotic species: issues for Yellowstone Park policy. Western North American Naturalist 61(3):257-260 [online] URL: https://scholarsarchive.byu.edu/ wnan/vol61/iss $3 / 2$

Hope D, Gries C, Zhu W, Fagan WF, Redman CL, Grimm NB, Nelson AL, Martin C, Kinzig A (2003) Socioeconomics drive urban plant diversity. Proc Natl Acad Sci U S A 100(15):8788-8792. https://doi. org/10.1073/pnas. 1537557100

Hülsmann M, von Wehrden H, Klein A-M, Leonhardt SD (2015) Plant diversity and composition compensate for negative effects of urbanization on foraging bumble bees. Apidologie 46:760-770. https:// doi.org/10.1007/s13592-015-0366-x 
Kremen C, Williams NM, Thorp RW (2002) Crop pollination from native bees at risk from agricultural intensification. Proc Natl Acad Sci U S A 99(26):16812-16816. https://doi.org/10.1073/pnas.262413599

Kretschmer L (2016) Attractiveness of ornamental flowers for pollinating insects in an urban area. University of Hohenheim, Master's thesis

Loram A, Thompson K, Warren PH, Gaston KJ (2008) Urban domestic gardens (XII): the richness and composition of the flora in five UK cities. J Veg Sci 19(3):321-330. https://doi.org/10.3170/2008-8-18373

Lowenstein DM, Matteson KC, Xiao I, Silva AM, Minor ES (2014) Humans, bees, and pollination services in the city: the case of Chicago, IL (USA). Biodivers Conserv 23:2857-2874. https://doi. org/10.1007/s10531-014-0752-0

Lowenstein DM, Matteson KC, Minor ES (2019) Evaluating the dependence of urban pollinators on ornamental, non-native, and 'weedy' floral resources. Urban Ecosyst 22:293-302. https://doi.org/10. 1007/s11252-018-0817-z

Mach BM, Potter DA (2018) Quantifying bee assemblages and attractiveness of flowering woody landscape plants for urban pollinator conservation. PLoS One 13(12):e0208428. https://doi.org/10.1371/ journal.pone.0208428

Matteson KC, Langellotto GA (2010) Determinates of inner city butterfly and bee species richness. Urban Ecosyst 13:333-347. https://doi. org/10.1007/s11252-010-0122-y

Matteson KC, Ascher JS, Langellotto GA (2008) Bee richness and abundance in New York City urban gardens. Ann Entomol Soc Am 101(1):140-150. https://doi.org/10.1603/0013-8746(2008) 101[140:BRAAIN]2.0.CO;2

Matteson KC, Grace JB, Minor ES (2013) Direct and indirect effects of land use on floral resources and flower-visiting insects across an urban landscape. Oikos 122(5):682-694. https://doi.org/10.1111/j. 1600-0706.2012.20229.x

Maxwell SL, Fuller RA, Brooks TM, Watson JEM (2016) Biodiversity: the ravages of guns, nets and bulldozers. Nature 536(7615):143145. https://doi.org/10.1038/536143a

McFrederick QS, LeBuhn G (2006) Are urban parks refuges for bumble bees Bombus spp. (Hymenoptera: Apidae)? Biol Conserv 129(3): 372-382. https://doi.org/10.1016/j.biocon.2005.11.004

McIntyre NE, Hostetler ME (2001) Effects of urban land use on pollinator (Hymenoptera: Apoidea) communities in a desert metropolis. Basic Appl Ecol 2(3):209-218. https://doi.org/10.1078/1439-1791-00051

McKinney ML (2006) Urbanization as a major cause of biotic homogenization. Biol Conserv 127(3):247-260. https://doi.org/10.1016/j. biocon.2005.09.005

Mulieri PR, Patitucci LD, Schnack JA, Mariluis JC (2011) Diversity and seasonal dynamics of an assemblage of sarcophagid Diptera in a gradient of urbanization. J Insect Sci 11(1):91-15. https://doi.org/ 10.1673/031.011.9101

Oksanen J, Blanchet FG, Friendly M, Kindt R, Legendre P, McGlinn D, Minchin PR, O'Hara R B, Simpson GL, Solymos P, Stevens MHH, Szoecs E, Wagner H (2019) Vegan: community ecology package. R package version 2.5-6. [online] URL: https://CRAN.R-project.org/ package $=$ vegan

Potts SG, Biesmeijer JC, Kremen C, Neumann P, Schweiger O, Kunin WE (2010) Global pollinator declines: trend, impacts and drivers. Trends Ecol Evol 25(6):345-353. https://doi.org/10.1016/j.tree. 2010.01.007

Powney GD, Carvell C, Edwards M, Morris RKA, Roy HE, Woodcock BA, Isaac NJB (2019) Widespread losses of pollinating insects in Britain. Nat Commun 10:1018. https://doi.org/10.1038/s41467019-08974-9

Pyšek P, Richardson DM, Rejmánek M, Webster GL, Williamson M, Kirschner J (2004) Alien plants in checklists and floras: towards better communication between taxonomists and ecologists. Taxon 53(1):131-143
R Core Team (2019) R: A language and environment for statistical computing. R Foundation for Statistical Computing, Vienna. [online] URL: https://www.R-project.org/

Rollings R, Goulson G (2019) Quantifying the attractiveness of garden flowers for pollinators. J Insect Conserv 23:803-817. https://doi.org/ 10.1007/s10841-019-00177-3

Salisbury A, Armitage J, Bostock H, Perry J, Tatchell M, Thompson K (2015) Enhancing gardens as habitats for flower-visiting aerial insects (pollinators): should we plant native or exotic species? J Appl Ecol 52(5):1156-1164. https://doi.org/10.1111/1365-2664.12499

Sánchez-Bayo F, Wyckhuys KAG (2019) Worldwide decline of entomofauna: a review of its drivers. Biol Conserv 232:8-27. https://doi. org/10.1016/j.biocon.2019.01.020

Shackleton K, Ratnieks FLW (2016) Garden varieties: How attractive are recommended garden plants to butterflies? J Insect Conservat 20: $141-148$

Shwartz A, Muratet A, Simon L, Julliard R (2013) Local and management variables outweigh landscape effects in enhancing the diversity of different taxa in a big metropolis. Biol Conserv 157:285-292. https://doi.org/10.1016/j.biocon.2012.09.009

Silva Mouga D, Feretti V, Sena J, Warkentin M, Santos A, Ribeiro C (2015) Ornamental bee plants as foraging resources for urban bees in southern Brazil. Agric Sci 6(3):365-381. https://doi.org/10.4236/ as.2015.63037

Somme L, Vanderplanck M, Michez D, Lombaerde I, Moerman R, Wathelet B, Wattiez R, Lognay G, Jacquemart A-L (2015) Pollen and nectar qualitiy drive the major and minor floral choices of bumble bees. Apidologie 46:92-106. https://doi.org/10.1007/s13592-0140307-0

Spearman C (1906) 'Footrule' for measuring correlation. Br J Psychol 2(1):89-108. https://doi.org/10.1111/j.2044-8295.1906.tb00174.x

Steffan-Dewenter I (2003) Importance of habitat area and landscape context for species richness of bees and wasps in fragmented orchard meadows. Conserv Biol 17(4):1036-1044. https://doi.org/10.1046/ j.1523-1739.2003.01575.x

Theodorou P, Albig K, Radzevičiūtè R, Settele J, Schweiger O, Murray TE, Paxton RJ (2017) The structure of flower visitor networks in relation to pollination across an agricultural to urban gradient. Funct Ecol 31(4):838-847. https://doi.org/10.1111/1365-2435.12803

Theodorou P, Radzevičiūtè R, Lentendu G, Kahnt B, Husemann M, Bleidorn C, Settele J, Schweiger O, Grosse I, Wubet T, Murray TE, Paxton RJ (2020) Urban areas as hotspots for bees and pollination but not a panacea for all insects. Nat Commun 11:576. https:// doi.org/10.1038/s41467-020-14496-6

United Nations, Department of Economic and Social Affairs, Population Division (2014) World Urbanization Prospects: The 2014 revision. Highlights (ST/ESA/SER.A/352)

van Dyck H, van Strien AJ, Maes D, van Swaay CAM (2009) Declines in common, widespread butterflies in a landscape under intense human use. Conserv Biol 23(4):957-965. https://doi.org/10.1111/j.15231739.2009.01175.x

Verboven HAF, Uyttenbroeck R, Brys R, Hermy M (2014) Different responses of bees and hoverflies to land use in an urban-rural gradient show the importance of the nature of the rural land use. Landsc Urban Plan 126:31-41. https://doi.org/10.1016/j.landurbplan.2014.02.017

Wenzel A, Grass I, Belavadi VV, Tscharntke T (2020) How urbanization is driving pollinator diversity and pollination - a systematic review. Biol Conserv 241:108321. https://doi.org/10.1016/j.biocon.2019.108321

Winfree R, Aguilar R, Vázquez DP, LeBuhn G, Aizen MA (2009) A meta-analysis of bees' responses to anthropogenic disturbance. Ecology 90(8):2068-2076. https://doi.org/10.1890/08-1245.1

Wojcik VA, McBride JR (2012) Common factors influence bee foraging in urban and wildland landscapes. Urban Ecosyst 15:581-598. https://doi.org/10.1007/s11252-011-0211-6 